MS30 Hydrogen bonding from theory to applications

Chairs: László Fábián, Nikoletta Bathori

\section{MS30-P1 Towards an Understanding of Hydrate Formation}

Alankriti Bajpai ${ }^{1}$, Michael J. Zaworotko ${ }^{1}$

1. Department of Chemical and Environmental Sciences, University of Limerick, Limerick, Republic of Ireland

email: alankriti.bajpai@ul.ie

Hydrates constitute an important class of multicomponent crystals pertinent to both crystal engineering $^{1-3}$ as well as pharmaceutical science ${ }^{4}$. The occurrence of hydrates in molecules containing solely strong $\mathrm{H}$-bond donors or $\mathrm{H}$-bond acceptors in particular has thus far been understudied. A comprehensive investigation of hydrate formation in $\mathrm{N}$-heterocyclic aromatic compounds that lack strong $\mathrm{H}$-bond donor groups was therefore performed. A Cambridge Structural Database (CSD) survey of 5- and 6-membered $\mathrm{N}$-heterocyclic aromatics, and hydrate screening experiments on a small set of compounds 1-11 (Figure 1) were conducted. The hydrate screening experiments involved: (i) crystallization from mixed solvent systems, (ii) slurry in water at ambient temperature, and (iii) exposure of anhydrous form to humid conditions (75\% relative humidity at $40{ }^{\circ} \mathrm{C}$ ). The results, which, when coupled with modelling experiments, provide much needed insights into the formation of hydrates and will be detailed.

\section{References:} 426.

1. Desiraju, G. R. J. Chem. Soc., Chem. Commun. 1991,

2. Infantes, L.; Fabian, L.; Motherwell, W. D. S. CrystEngComm 2007, 9, 65.

3. Clarke, H. D.; Arora, K. K.; Bass, H.; Kavuru, P.; Ong, T. T.; Pujari, T.; Wojtas, L.; Zaworotko, M. J. Cryst. Growth Des. 2010, 10, 2152.

4. Khankari, R. K.; Grant, D. J. W. Thermochim. Acta 1995, 248, 61 .
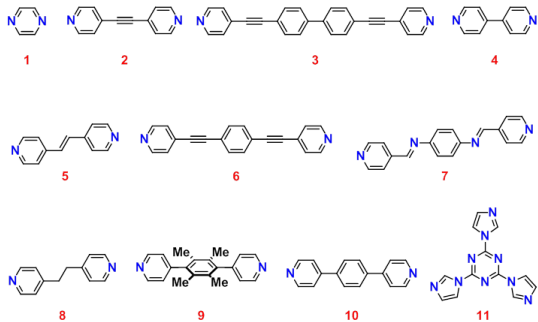

Figure 1. $N$-heterocyclic compounds investigated for hydrate screening.

Keywords: Crystal engineering, hydrogen bonding, hydrate screening 